\title{
KEJADIAN PREEKLAMPSIA DI BLU RSUP PROF DR. R.D. KANDOU MANADO TAHUN 2012
}

\author{
${ }^{1}$ Junior V. D. Sengkej \\ ${ }^{2}$ Juneke J. Kaeng \\ ${ }^{2}$ Max Rarung
}

\author{
${ }^{1}$ Kandidat Skripsi Fakultas Kedokteran Universitas Sam Ratulangi Manado \\ ${ }^{2}$ Bagian Obstetri - Ginekologi Fakultas Kedokteran Universitas Sam Ratulangi Manado \\ Email : juniorsengkej@yahoo.com
}

\begin{abstract}
Abstact: Maternal Mortality and Perinatal Mortality in Indonesia is still high . According to the Indonesian Demographic and Health Survey (2007 ) The maternal mortality rate is 228 per 100,000 live births . Which is a major cause of maternal deaths in Indonesia in addition to bleeding is pre- eclampsia or eclampsia and causes of perinatal mortality are high . The purpose of this study to describe the incidence of risk factors for pre - eclampsia occurring in the department of Prof. . Dr. . R. D. Kandou in 2012 . In this study using a retrospective descriptive method. The research data collected from medical record mild preeclampsia, severe preeclampsia, superimposed preeclampsia in 2012 . The conclusion of this study, cases of preeclampsia results of this study, descriptive mild preeclampsia/severe preeclampsia/superimposed preeclampsia in the department of Prof. . R.D. Kandou Manado in 2012 mostly aged 20-35 years with sekundigravida parity , and is pregnant more than 2 years , and rarely accompanied by a history of hypertension, no history of multiple births and body mass index obesse ie with BMI> 30 .
\end{abstract}

Keyword: Pre-eclampsia, pregnancy.

\begin{abstract}
Abstrak : Kematian Ibu dan Angka Kematian Perinatal di Indonesia masih tinggi. Menurut Survei Demografi dan Kesehatan Indonesia (2007) Angka kematian ibu adalah 228 per 100.000 kelahiran hidup. Yang menjadi sebab utama kematian ibu di Indonesia di samping perdarahan adalah pre-eklampsia atau eklampsia dan penyebab kematian perinatal yang tinggi. Tujuan dari penelitian ini untuk mengetahui gambaran dari faktor risiko kejadian pre-eklampsia yang terjadi di RSUP Prof. Dr. R. D. Kandou tahun 2012. Dalam penelitian ini menggunakan metode deskriptif retrospektif. Data penelitian dikumpul dari rekam medik preeklampsia ringan, preeklampsia berat, superimposed preeklampsia di tahun 2012. Kesimpulan dari penelitian ini, kasus preeklampsia Hasil penelitian ini, secara deskriptif penderita preeklampsia ringan/preeklampsia berat/superimposed preeklampsia di RSUP Prof. R.D. Kandou Manado tahun 2012 kebanyakan berusia 2-35 tahun dengan paritas sekundigravida, dan berjarak hamil lebih dari 2 tahun, serta jarang disertai riwayat hipertensi, tidak memiliki riwayat persalinan ganda dan indeks massa tubuh yang obesse yaitu dengan IMT $>30$.
\end{abstract}

Kata Kunci: Pre-eklampsia, kehamilan.

Kematian Ibu dan Angka Kematian Perinatal di Indonesia masih tinggi. Menurut Survei Demografi dan Kesehatan Indonesia (2007) Angka kematian ibu adalah 228 per 100.000 kelahiran hidup. Jika dibandingkan dengan target yang ingin dicapai oleh pemerintah pada tahun 2015 sebesar
102/100.000 kelahiran hidup angka tersebut masih tergolong tinggi. ${ }^{1}$ Pre-eklampsia dan eklampsia merupakan kesatuan penyakit, yakni yang langsung disebabkan oleh kehamilan, walaupun belum jelas bagaimana hal ini terjadi, istilah kesatuan penyakit diartikan bahwa kedua peristiwa 
dasarnya sama karena eklampsia merupakan peningkatan dari pre-eklampsia yang lebih berat dan berbahaya dengan tambahan gejala-gejala tertentu. $^{2}$ tidak hanya satu faktor yang menyebabkan ini terjadi, ada banyak faktor yang menyebabkan terjadinya preeklampsia dan eklampsia (multiple causation). Faktor yang sering ditemukan sebagai faktor risiko antara lain nulipara, kehamilan ganda, usia kurang dari 20 tahun atau lebih dari 35 tahun, punya riwayat keturunan, dan obesitas. Namun diantara faktor-faktor yang ditemukan sering kali sukar ditentukan mana yang menjadi sebab dan mana yang menjadi akibat. ${ }^{2}$

\section{METODE PENELITIAN}

Penelitian ini dilaksanakan di bagian Rekam Medik BLU RSUP.Dr.R.D.Kandou Manado pada bulan November-Desember 2013. Metode penulisan yang dilakukan adalah penelitian yang bersifat deskriptif retrospektif. Penelitian deskriptif retrospektif merupakan penelitian yang meninjau data-data pada masa lampau.. sampel yang digunakan pada penelitian ini adalah seluruh kasus pre-eklampsia ringan, pre-eklampsia berat, dan superimposed preeklampsia yang ada di RSUP Prof.Dr.R.D. Kandou Manado tahun 2012. Variabel bebas penelitian yang akan diteliti adalah usia, paritas, jarak kehamilan, riwayat kehamilan ganda, riwayat hipertensi, riwayat gizi (indeks massa tubuh), dan variabel terikat adalah preeklampsia ringan, preeklampsia berat, superimposed preeklampsia. Cara kerja yang dipakai pada penelitian ini terdiri dari, pengumpulan data secara retrospektif dari data yang ada di bagian Rekam Medik BLU RSUP Dr.R.D.Kandou Manado tahun 2012, dan pengolahan data dilakukan secara deskriptif dan komputerisasi yang disajikan dalam bentuk tabel.

\section{HASIL PENELITIAN}

Berikut ini merupakan hasil penelitian yang dilakukan di RSUP Prof R.D. Kandou Tahun untuk mencari gambaran dari faktor resiko kejadian pre-eklampsia pada tahun 2012 dengan menggunakan metode pendekatan deskriptif retrospektif, yaitu dengan melihat kembali status penderita yang terdapat dalam Rekam Medis.

\section{Distribusi responden berdasarkan usia ibu}

Tabel 1. Distribusi jumlah kejadian preeklampsia ringan/preeklampsia berat/ superimposed preeklampsia berdasarkan usia Ibu di RSUP Prof R.D. Kandou Manado Tahun 2012

\begin{tabular}{cccc}
\hline No & $\begin{array}{c}\text { Kelompok } \\
\text { Usia }\end{array}$ & Jumlah & Presentase \\
\hline $\mathbf{1}$ & $<20$ Tahun & 11 & 9,8 \\
$\mathbf{2}$ & $20-35$ Tahun & 70 & 62,5 \\
$\mathbf{3}$ & $>35$ Tahun & 31 & 27,7 \\
Jumlah & & 112 & 100,0 \\
\hline
\end{tabular}

\section{Distribusi responden berdasarkan paritas}

Tabel 2. Distribusi jumlah kejadian preeklampsia ringan/preeklampsia berat/ superimposed preeklampsia di RSUP Prof R.D. Kandou Manado Tahun 2012 berdasarkan paritas ibu

\begin{tabular}{cccc}
\hline No. & Paritas & Jumlah & Presentasi \\
\hline $\mathbf{1}$ & Primigravida & 38 & 33,9 \\
$\mathbf{2}$ & Sekundigravida & 40 & 35,7 \\
$\mathbf{3}$ & Multigravida & 34 & 30,4 \\
Jumlah & & 112 & 100,0 \\
\hline
\end{tabular}

\section{Distribusi responden berdasarkan jarak kehamilan}

Tabel 3. Distribusi jumlah kejadian preeklampsia ringan/preeklampsia berat/ superimposed preeklampsia di RSUP Prof R.D. Kandou Manado Tahun 2012 berdasarkan jarak kehamilan

\begin{tabular}{cccc}
\hline No. & $\begin{array}{c}\text { Jarak } \\
\text { Kehamilan }\end{array}$ & Jumlah & Presentasi \\
\hline $\mathbf{1}$ & $\leq 2$ Tahun & 13 & 11,6 \\
$\mathbf{2}$ & $>2$ Tahun & 99 & 88,4 \\
Jumlah & & 112 & 100,0 \\
\hline
\end{tabular}


Sengkej, Kaeng, Rarung; Kejadian Preeklampsia di BLU RSUP Prof. DR. R. D. Kandou...

\section{Distribusi responden berdasarkan riwayat hipertensi}

Tabel 4. Distribusi jumlah kejadian preeklampsia ringan/preeklampsia berat/ superimposed preeklampsia di RSUP Prof R.D. Kandou Manado Tahun 2012 berdasarkan riwayat hipertensi

\begin{tabular}{cccc}
\hline No & $\begin{array}{c}\text { Riwayat } \\
\text { Hipertensi }\end{array}$ & Jumlah & Presentase \\
\hline $\mathbf{1}$ & Ya & 22 & 19,7 \\
$\mathbf{2}$ & Tidak & 90 & 80,3 \\
Jumlah & & 112 & 100,0 \\
\hline
\end{tabular}

\section{Distribusi responden berdasarkan riwayat persalinan ganda}

Tabel 5. Distribusi jumlah kejadian preeklampsia ringan/preeklampsia berat/ Superimposed Preeklampsia di RSUP Prof R.D. Kandou Manado Tahun 2012 berdasarkan riwayat persalinan ganda

\begin{tabular}{llll}
\hline No & $\begin{array}{l}\text { Riwayat } \\
\text { Persalinan } \\
\text { Ganda }\end{array}$ & Jumlah & Presentase \\
\hline $\mathbf{1}$ & Ya & 0 & 0 \\
$\mathbf{2}$ & Tidak & 112 & 100,0 \\
Jumlah & & 112 & 100,0 \\
\hline
\end{tabular}

\section{Distribusi responden berdasarkan Indeks Massa Tubuh pasien}

Tabel 6. Distribusi jumlah kejadian preeklampsia ringan/preeklampsia berat/ superimposed preeklampsia di RSUP Prof R.D. Kandou Manado Tahun 2012 berdasarkan indeks massa tubuh pasien

\begin{tabular}{llll}
\hline No & IMT & Jumlah & Presentase \\
\hline $\mathbf{1}$ & $<18,5$ & 1 & 0,9 \\
$\mathbf{2}$ & $18,5-$ & 16 & 14,3 \\
& 24,9 & & \\
\hline $\mathbf{3}$ & $25-29,9$ & 43 & 38,4 \\
\hline $\mathbf{4}$ & $>30$ & 52 & 46,4 \\
Jumlah & & 112 & 100,0 \\
\hline
\end{tabular}

\section{BAHASAN}

\section{Distribusi kelompok usia Ibu}

Kejadian preeklampsia di RSUP Prof. R.D. Kandou Manado pada tahun 2012 berdasarkan kelompok usia ibu lebih didominasi pada kelompok usia ibu 20-35 tahun dengan jumlah 70 orang (62,5\%), kelompok usia lebih dari 35 tahun sebanyak 31 orang $(27,7 \%)$, dan angka terendah terjadi pada usia ibu kurang dari 20 tahun yaitu sebanyak 11 orang (9,8\%).

Menurut teori yang ada preeklampsia lebih sering didapatkan pada masa awal dan akhir usia reporduktif yaitu usia remaja atau di atas 35 tahun. Ibu hamil $<20$ tahun mudah mengalami kenaikan tekanan darah dan lebih cepat menimbulkan kejang. Sedangkan umur lebih 35 tahun juga merupakan faktor predisposisi untuk terjadinya preeklampsia. Hipertensi dan diabetel mellitus merupakan faktor penyebab terjadinya preeklampsia. Jadi wanita yang berada pada awal atau akhir usia reproduktif lebih rentan menderita preeklampsia.

Dari hasil penelitian ini tidak sesuai dengan teori penyebab preeklampsia di RSUP Prof. R.D. Kandou Manado pada tahun 2012 berdasarkan kelompok usia justru lebih di dominasi oleh kelompok usia ibu 20-35 tahun, hal ini disebabkan dari data seluruh responden ibu hamil banyak yang masuk kategori primigravida ataupun masuk kategori sekundigravida namun dengan jarak kehamilan pendek dengan demikian ibu hamil masih dalam kategori produktif

\section{Paritas}

Kejadian preeklampsia di RSUP Prof. R.D. Kandou Manado pada tahun 2012 berdasarkan paritas hampir sama rata, dimana kelompok ibu sekundigravida yang berjumlah 40 orang $(35,7 \%)$ hanya berbeda sedikit dengan kelompok ibu primigravida yang berjumlah 38 orang (33,9\%), sedangkan kelompok ibu multigravida berjumlah 34 orang (30,4.Dari data The New England Journal of Medicine di katakan teori preeklampsia yaitu resiko preeklampsia umumnya lebih rendah pada kehamilan kedua dibanding dengan 
kehamilan pertama, akan tetapi apabila pasangan dari ibu yang melahirkan ini tetap sama, hal ini dapat dijelaskan bahwa pada ibu terjadi adaptasi dari antigen pasangan yang sama. ${ }^{3}$ Dari hasil penelitian ini sendiri terbukti benar teori bahwa primigravida atau kehamilan pertama ini merupakan salah satu faktor resiko preeklampsia di RSUP R.D. Kandou Tahun 2012, walaupun pada penelitian ini hasil yang didapat tidak jauh perbedaanya.

\section{Jarak Kehamilan}

Kejadian preeklampsia di RSUP Prof. R.D. Kandou Manado pada tahun 2012 berdasarkan jarak kehamilan sangat didominasi oleh kelompok ibu yang mempunyai jarak kehamilan diatas 2 tahun yaitu sebanyak 99 orang ( 88,4\%) dan sisanya yaitu jarak kehamilan dibawah 2 tahun yaitu sebanyak 13 orang ( $11,6 \%)$. Dari teori yang di dapat di The New England Journal of Medicine resiko preeklampsia meningkat sesuai dengan usia ibu, hal ini dapat dikaitkan dengan peningkatan resiko preeklampsia dengan bertambah jauhnya jarak kehamilan dari ibu, dan dari hasil penelitian ini menunjukan bahwa jarak kehamilan diatas 2 tahun lebih berpontensi untuk mendapatkan preeklampsia dibanding dengan kehamilan yang berjarak kurang dari 2 tahun menunjang teori yang ada. ${ }^{3}$

\section{Riwayat hipertensi}

Kejadian preeklampsia di RSUP Prof. R.D. Kandou Manado pada tahun 2012 berdasarkan riwayat hipertensi didominasi oleh kelompok ibu yang tidak mempunyai riwayat hipertensi yang berjumlah 90 orang (80,3\%) sedangkan kelompok ibu yang memiliki riwayat hipertensi hanya 22 orang (19,7\%). Hasil penelitian ini menunjukan bahwa teori preeklampsia yaitu salah satu faktor predisposisi terjadinya pre-eklampsia atau eklampsia adalah adanya riwayat hipertensi kronis, atau penyakit vaskuler hipertensi sebelumnya, atau hipertensi esensial $^{6}$ kurang tepat karena pada penelitian ini preeklampsia terjadi pada ibu hamil yang tidak mempunyai riwayat hipertensi, hal ini dapat dijelaskan karena kebanyakan dari data yang didapat bahwa kebanyakan ibu masih dalam primigravida dan sekundigravida dengan usia yang masih reproduktif.

\section{Riwayat persalinan ganda}

Kejadian preeklampsia di RSUP Prof. R.D. Kandou Manado pada tahun 2012 berdasarkan riwayat persalinan ganda mendapatkan satu hasil yang dominan yaitu yang tidak memiliki riwayat persalinan ganda yaitu 112 orang (100,0\%). Teori mengatakan bahwa kehamilan ganda melipat gandakan resiko dari preeklampsia, hal ini dikarenakan berat placenta lebih besar pada diabetes dan kehamilan ganda. ${ }^{5}$ Dari hasil ini diketahui bahwa persalinan ganda tidak memiliki resiko untuk terjadinya preeklampsia, akan tetapi data yang di dapat hanyalah pada tahun 2012 saja, dengan demikian jika dilakukan penelitian dalam jangka waktu yang lebih luas akan mendapat hasil yang berbeda juga.

\section{Indeks Massa Tubuh}

Kejadian preeklampsia di RSUP Prof. R.D. Kandou Manado pada tahun 2012 berdasarkan indeks massa tubuh ibu memperoleh hasil 52 orang untuk kategori obese (IMT >30), 43 orang untuk over weight (IMT 25-29,9), 16 orang untuk kategori Normal (IMT 18,5-24,9) dan 1 orang untuk underweight (IMT <18,5). Didapatkan dari hasil penelitian ini ibu hamil yang obese atau overweight dapat terkena preeklampsia hal ini di dukung teori yaitu semakin besar berat badan seseorang semakin banyak darah yang terdapat dalam tubuh dan semakin sulit juga jantung untuk memompa darah, maka dari itu dapat terjadi preeklampsia

\section{SIMPULAN}

a. Kejadian Preeklampsia ringan, Preeklampsia berat, Superimposed Preeklampsia di RSUP Prof R.D. Kandou Manado Tahun 2012 berdasarkan kelompok usia terbanyak 
Sengkej, Kaeng, Rarung; Kejadian Preeklampsia di BLU RSUP Prof. DR. R. D. Kandou...

pada kelompok usia 20-35 tahun yaitu sebanyak 62,5\%.

b. Kejadian Preeklampsia ringan, Preeklampsia berat, Superimposed Preeklampsia di RSUP Prof R.D. Kandou Manado Tahun 2012 berdasarkan paritas terbanyak pada kelompok paritas sekundigravida yaitu sebanyak $35,7 \%$

c. Kejadian Preeklampsia ringan, Preeklampsia berat, Superimposed Preeklampsia di RSUP Prof R.D. Kandou Manado Tahun 2012 berdasarkan jarak kehamilan terbanyak pada kelompok ibu dengan jarak kehamilan lebih dari 2 tahun yaitu sebanyak 88,4\%

d. Kejadian Preeklampsia ringan, Preeklampsia berat, Superimposed Preeklampsia di RSUP Prof R.D. Kandou Manado Tahun 2012 berdasarkan riwayat hipertensi terbanyak pada kelompok ibu yang tidak memiliki riwayat hipertensi yaitu sebanyak 80,3\%

e. Kejadian Preeklampsia ringan, Preeklampsia berat, Superimposed Preeklampsia di RSUP Prof R.D. Kandou Manado Tahun 2012 berdasarkan riwayat persalinan ganda terbanyak pada yang tidak memiliki riwayat persalinan ganda yaitu sebanyak 100\%

f. Kejadian Preeklampsia ringan, Preeklampsia berat, Superimposed Preeklampsia di RSUP Prof R.D. Kandou Manado Tahun 2012 berdasarkan indeks massa tubuh terbanyak pada obesse yaitu pada IMT > 30 sebanyak 46,4\%

Hasil penelitian ini, secara deskriptif penderita preeklampsia ringan/preeklampsia berat/superimposed preeklampsia di RSUP Prof. R.D. Kandou Manado tahun 2012 kebanyakan berusia 20-35 tahun dengan paritas sekundigravida, dan berjarak hamil lebih dari 2 tahun, serta jarang disertai riwayat hipertensi, tidak memiliki riwayat persalinan ganda dan indeks massa tubuh yang obesse yaitu dengan IMT > 30

\section{SARAN}

a. Untuk mahasiswa fakultas kedokteran penelitian ini dapat dijadikan tambahan data dalam penelitian preeklampsia berikutnya.

b. Untuk bidang pelayanan kesehatan dapat menjadi data tambahan tentang gambaran faktor resiko preeklampsia di RSUP Prof. DR. R.D. Kandou

\section{DAFTAR PUSTAKA}

1. BPS dan ORC. Macro Survey Demografi dan Kesehatan Indonesia 2002-2003, Claverton, Maryland, USA; ORC Macro, 2003.

2. Prawirohardjo Sarwono; Ilmu Kebidanan. Ed.3, Jakarta, 2008.

3. Skjaerven, Rolv, PhD ; Wilcox, Allen J, MD, PhD; Lie, Rolv T, PhD. The New England Journal of Meicine 346.1 (Jan 3, 2002) : 33-8

4. Pipkin, Fiona Broughton, Dphil, FRCOG. The New England Journal of Medicine 344.12 (Mar 22, 2001): 925-926

5. Crowther $\mathbf{C}$; Eclampsi at Harare Maternity Hospital; An Epidemiological Study. Sout Art Med J 1985;68: 927-929

6. Ben-zion Taber, MD. Kapita selekta. Kedaruratan Obstetri \& Ginecologi; Alih bahasa; Teddy Supriyadi; Johanes Gunawan; Editor Melfiawati S, Ed 2, Jakarta, EGC.1994 